trative of economic minerals and metals, economic botany, and the deterioration of timbers, have been set up. It should be noted that as from January 23 the name of this Museum has been changed to the Institute of Applied Science of Victoria.

\section{Swimming Ability of Reptiles}

Systematic experiments have been carried out by R. R. Tercafs to test the swimming ability of nonaquatic reptiles (Bulletins de la Société Royale de Zoologie d'Anvers. No. 20. Pp. 19 (6 planches). Anvers: Société Royale de Zoologie d'Anvers, 1961). Among snakes, the following species have been studied: Vipera verus, Boa canina, Thamnophis sauritus, Coronella austriaca, Chlorosoma schottii, Vipera ammodites and Eryx johnii. The first two species cannot co-ordinate their movements, nor keep their heads out of water; the remaining species can swim very well, by movements similar to those they make on the ground. Some lizards (Trachydosaurus rugosus, Tarentol mauritanica, Chamaeleo dilepis and Anguis fragilis) have the same behaviour: they go forward in water by walking (thus using the same movements as on the ground). On the other hand, other species (Lacerta viridis, Tiliqua scinoides, Lacerta muralis, Crocodilurus lacertinus, Iguana iguana and Tropidurus torquatus) change their usual movements and swim in the same way as aquatic Caudata: they keep their members close to the body and go forward by waving with body and tail. The adaptation to swimming seems to be more ethological than morphological; the inability to swim of some reptiles might be explained by the lack of nervous co-ordination in response to stimuli in water; in the same way integration of these stimuli could explain the adaptation to swimming of some reptiles. Two adaptive stages exist, co-ordinated movements like the movements on the ground and swimming movements, identical with those of aquatic Caudata.

\section{Reactions of Salt Solutions and Calcium Chloride on Mortar and Concrete}

THE December issue of the Australian Journal of Science, 2, No. 4, December 1960) contains two significant communications to concrete specialists; one by J. A. Roberts and H. E. Vivian on "The Widening of Expansion Cracks in Mortar by Salt Solutions", the other by M. Lawrence and H. E. Vivian on "The Action of Calcium Chloride on Mortar and Concrete". In the former paper a new mechanism is described by which pre-existing cracks in mortar are enlarged and expanded by salt solutions, for example calcium nitrate and sodium silicate. Action of salt solutions tends to accelerate disintegration of concrete by opening of fine cracks therein, especially where the concrete is exposed to weathering conditions, for example roads. A conclusion is reached that concrete road-surfacings may be damaged by application of such salts as calcium chloride for the purpose of removing ice. It may be that certain aggregates may be similarly affected by salt reaction. In the second paper cited, it is shown that severe reaction, causing disruption of mortar and concrete, occurs when strong calcium chloride solution comes into contact with them. The disruption is similar to that caused by sulphate attack, but in this case it is considered to be due to formation of chloroaluminate, derived from the 'susceptible' compound in cement paste, tricalcium aluminate hydrate. It is anticipated that control of severe sulphate or chloride attack may develop from further work by employing "some method of rapidly modifying the susceptible hydration products of tricalcium aluminate and tetra-calcium aluminoferrite to ensure that no reactable material is available after the cement sets".

\section{U.S. National Science Foundation: Office of Antarctic Programs}

AN Office of Antarctic Programs has been established within the National Science Foundation. This new Office replaces the Antarctic Research Program, formerly a part of the Foundation's Office of Special International Programs. Dr. Thomas O. Jones has been appointed head of the new Office. Dr. Albert P. Crary has been appointed chief scientist and will also serve as science adviser on Antarctica to the director, Dr. Alan T. Waterman. The Office of Antarctica Programs is responsible for the United States Antarctic Research Program, which is the name used in the field to include all U.S. scientific work carried out in Antarctica. Scientists from colleges, universities and Government agencies, working under sponsorship of the National Science Foundation, carry out research in biology, geodesy and cartography, geology, glaciology, meteorology, oceanography, upper atmosphere physics and seismology.

\section{U.K. Courses in Nuclear Energy, 1961-63}

A catalogue entitled Nuclear Studies has been compiled by the Science Department of the British Council. This lists courses in pure and applied sciences concerning the use and development of nuclear energy which may be undertaken in the United Kingdom. These courses are full-time, and are generally of one week or more duration. The information provided by the catalogue includes notes on each of the courses and the institution at which it takes place; also the fee and the qualifications required for participation. Further information can be obtained from the Science Department, The British Council, 65 Davies Street, London, W.1.

Eleanor Roosevelt International Cancer Fellowships

THE International Union against Cancer, by means of funds made available by the Eleanor Roosevelt Cancer Foundation, will award annually fellowships for research on cancer. These are senior post-doctoral awards designed for the support of persons who, as full-time members of the staff of universities, teaching hospitals, research laboratories or other institutions, have demonstrated interest and ability or promise as independent investigators in the field of research on basic cancer, and who wish to broaden their experience by a period of study in another country. The duration of the fellowships ordinarily will be one year, but this period may be extended or shortened in special circumstances. The stipend will be based on the current salary of the applicant and the salary of persons of comparable qualifications in the place where the applicant expects to study. Application forms can be obtained from the International Union against Cancer, P.O. Box 400, Geneva 2.

\section{Nutrition and Metabolic Defects}

THE Nutrition Society is organizing a symposium on "Nutrition and Metabolic Defects", to be held at the Laboratory of Physiology, Oxford, on July 15. The programme will include the following subjects: historical aspects of inborn errors of metabolism, by Dr. H. M. Sinclair (Oxford); clinical aspects of 